\title{
Stenting of Unprotected Left Main Coronary Artery in a Patient with Cardiogenic Shock
}

\author{
Bedson José Lopes de Sá, Mary Jane Martins Rocha, José Bonifácio Barbosa, Carlos Gama, \\ Raimundo João Costa Furtado
}

São Luís, MA - Brazil

\begin{abstract}
A 64-year-old female presented with pulmonary edema and cardiogenic shock after coronary arteriography that showed severe suboclusive lesion in the left main coronary artery (LMCA) in a dominant left coronary system. The patient succesfully underwent urgent angioplasty with stent deployment in the LMCA. After an uneventful period, the patient was discharged at day six.
\end{abstract}

Percutaneous transluminal coronary angioplasty of unprotected LMCA is considered a high-risk procedure, contraindicated in elective situations; however, it can be performed in specific cases of clinically unstable patients with acute myocardial infarction (AMI), unstable angina with contraindication for surgery, or critical patients in whom surgical mortality would be very high. In these cases, angioplasty together with stenting may have more advantages than angioplasty alone, such as less acute, and subacute complications and a lower restenosis rate. We report here a case of a patient in cardiogenic shock due to instabilization of a subocclusive lesion in LMCA treated with urgent stenting.

\section{Case Report}

A 64-year-old female diabetic patient with mitral stenosis had undergone open commissurotomy 4 years earlier. She had many episodes of substernal chest pain, and profuse sweating followed by dyspnea unrelated to effort in the prior two weeks. She was recommended for heart catheterization and coronary angiography.

Coronary angiography was performed on October, 6 , 1998 and after right femural arterial venous puncture two $6 \mathrm{~F}$ sheaths were placed. This study was conducted first with right heart catheterization for evaluation and registration of right atrial pressure (RA), right ventricular pressure( $R V)$, pulmonary artery pressure (PA), and pulmonary capillary wedge pressure ( PCW) followed by right ventriculography.

The pressures were: $\mathrm{RA}$ mean $=5 \mathrm{mmHg}$; RV $=45$ /

Hospital - São Luís

Mailing adress: Bedson José Lopes de Sá - Rua das Figueiras, Qda 20 - Bl. A apto 302 - 65017-150 - São Luís, MA - Brazil.

Received on $1 / 7 / 99$

Accepted on 4/28/99
$5 \mathrm{mmHg} ; \mathrm{PA}=45 / 18 \mathrm{mmHg} ; \mathrm{PCW}$ mean $=22 \mathrm{mmHg}$. A pattern of left atrium emptying compatible with moderate mitral stenosis was detected in the left phase of the right ventriculography.

After that, cinecoronariography and left ventriculography studies were carried out. Judkins coronary catheters (JR and JL) and pigtail catheters size 6F were used. The right coronary artery (RCA) was shown to have moderate lesions in the ostia; the left coronary artery (LCA) was barely cannulated, and its study showed a severe subocclusive stenosis, (>90\%) in the middle portion (fig. 1). The left ventriculography $(\mathrm{LV})$ showed severe hypokinesis in the apical wall and mild hypokinesis in the other walls. The pressures in the left ventricle (LV) and aorta (Ao) were: $L V=120$ / $15 \mathrm{mmHg}$; $\mathrm{Ao}=120 / 60 \mathrm{mmHg}$.

After the procedure, the patient was sent to the intensive care unit (ICU) in stable condition without complaints. The vascular sheaths were maintained. The patient was considered for surgery; routine evaluation, and a presurgical workup were required.

Approximately one hour after the admission to the ICU, the patient started feeling oppressive substernal chest pain radiating for the back followed by dyspnea and profuse sweating. The EKG showed a slight ST depression. The patient rapidly evolved to acute pulmonary edema and respiratory distress requiring endotracheal intubation and mechanical ventilation support. Her blood pressure levels fell to 50/30 $\mathrm{mmHg}$, and the ST segment showed 5mm ST depression in D1, aVL, V1 - V6. Some nonsustained episodes of ventricular tachycardia occurred. The patient was sedated and received full heparinization with a $2 \%$ continuous lidocaine infusion, furosemide IV, subcutaneous insulin according to glycemia and dobutamine $8 \mu \mathrm{g} / \mathrm{kg} / \mathrm{min}$. There was an improvement in pulmonary congestion, although the patient remained in shock. Due to the patient's critical status, myocardial revascularization would have caused a great risk of mortality. It was decided that catheter intervention on the LCA would save time.

The $6 \mathrm{~F}$ introducer was placed in the femoral vein and a temporary pacemaker electrode was located in the right ventricle then the arterial sheath was replaced by an $8 \mathrm{~F}$ one. An Amplax guide catheter L2 8F with sideholes was used to cannulate the LCA. The guidewire, steerable 0.014 , was then passed across the target stenosis visualized by fluo- 


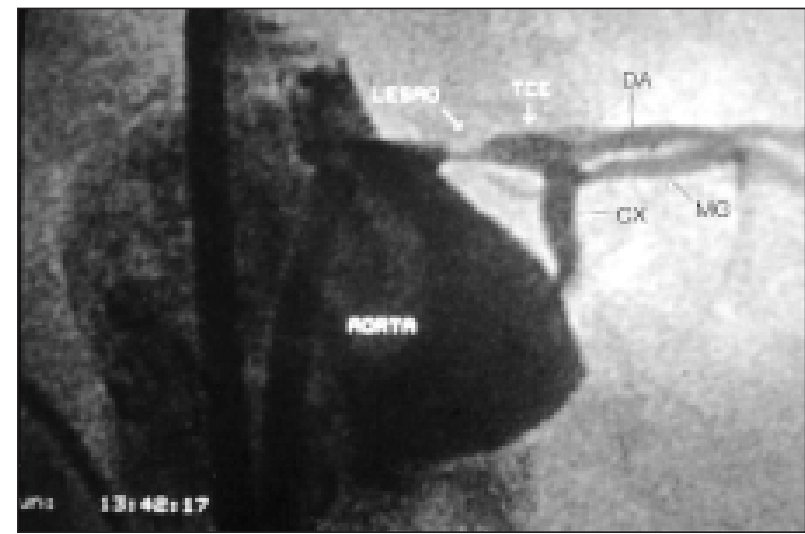

Fig. 1 - Left coronary angiography and ventriculography study. LCA dominant with severe subocclusive stenosis in the middle portion.

roscopy view and positioned in the left anterior descending artery. A Europass $2.0 \times 20 \mathrm{~mm}$ was introduced. At this time the blood pressure in the ascending aorta was $50 / 40 \mathrm{mmHg}$, and the ST segment depression was significant. Heparinization was maintained to assure a TCA of around 350s.

The balloon was inflated over the lesion at 10atm pressure for $10 \mathrm{sec}$. No arrhythmia was observed and after balloon deflation, blood pressure rose to $70 / 40 \mathrm{mmHg}$. The Europass catheter was replaced by a Lifestream $3.0 \times 20 \mathrm{~mm}$ perfusion balloon, inflated to $4 \mathrm{~atm}$ for $20 \mathrm{sec}$. A Nir Primo stent was used attached to a $3.5 \times 9 \mathrm{~mm}$ balloon, located over the lesion and released successfully at 16 atm pressure for 15 sec. Ultimate injections showed TIMI 3 flow with $0 \%$ of residual stenosis (fig. 2).

There was an improvement of blood pressure level while the patient was in the catheterization laboratory, and the patient was admitted to the ICU with BP 100/70mmHg. There was also a decrease in ST depression, which was $2 \mathrm{~mm}$ on the EKG taken immediately after the procedure. The patient received aspirin $200 \mathrm{mg} /$ daily, ticlopidine $250 \mathrm{mg}$ twice a day, and dobutamine $5 \mathrm{mcg} / \mathrm{kg} / \mathrm{min}$ in continuous infusion as complementary therapeutics. The patient showed gradual improvement in both clinical and hemodynamical parameters, being extubated on September 8, 1998. The dobutomine infusion was suspended on the same day. Maximum level of CKMB was $124 \mathrm{mg} / \mathrm{dL}, 12$ hours after the procedure with a later decline. The patient was discharged from the ICU on September 9, 1998, asymptomatic, and was mantained on ticlopidine and aspirin in the same doses as mentioned above, oral furosemide $40 \mathrm{mg} /$ daily and glibenclamide. On physical examination the patient was in good health with no pulmonary rales or diastolic murmur of mitral stenosis. EKG showed sinus rhythm, and left atrial and ventricular hypertrophy. There was no Q wave. One day after ICU discharge, the patient had one episode of acute atrial fibrillation with a heart rate of $94 \mathrm{bpm}$ without hemodynamic impairment. She underwent DC defibrillation with $200 \mathrm{~J}$,

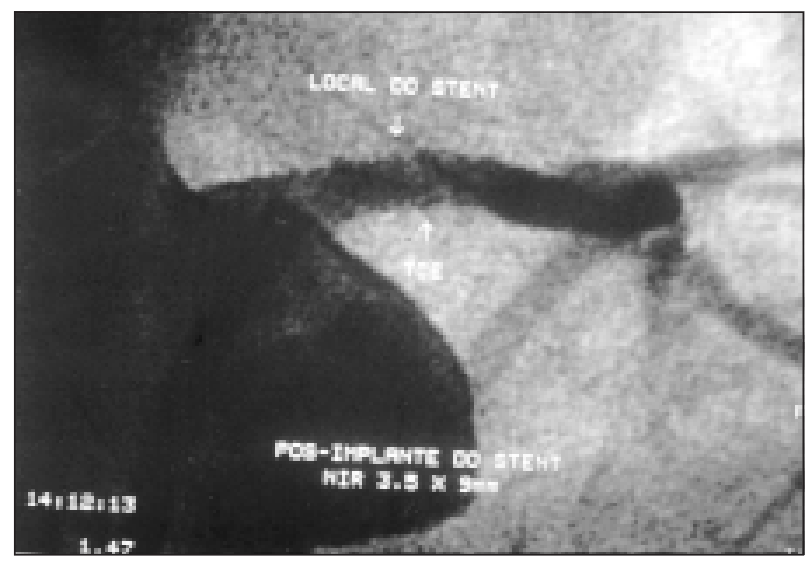

Fig. 2 - Success Stenting deployment with no residual stenosis.

achieving reversion to sinus rhythm without major adverse events. As a maintenance drug, amiodarone 200mg b.i.d was administred.

Hospital discharge was given on September 12, 1998, and the patient remains asymptomatic and stable.

\section{Discussion}

Unprotected stenosis in the LMCA has been regarded as an absolute indication for bypass surgery and is usually considered prohibitive for treatment with a catheter. However, there are many reports that show that in selected cases it is possible to achieve good results with angioplasty and coronary stenting, decreasing morbidity and mortality as well as length of hospital stay. At first, the long-term results with the use of a balloon catheter for unprotected left main coronary artery were disappointing, which reinforced the contraindication for the procedure. The advent of stents gave a new focus to the matter. Park et al performed PTCA with stenting deployment in unprotected LMCA in 42 patients with preserved left ventricular function. Fortyone of these patients refused surgery. Their results were encouraging, achieving immediate success in all cases. After six months, the restenosis rate was $22 \%$. The only death occurred two days after revascularization surgery in a patient with intra-stent restenosis. According to the authors, stent selection is also a determining factor of success. Due to a high concentration of electric fibers in the ostial and proximal segment of the LMCA, the lesions at this point have more elastic recoil and would be optimally treated with the use of tubular stents, coil stents being used mainly in distal lesions. Some reports have also shown that in impending occlusion of the LMCA in unstable patients this procedure can be lifesaving, avoiding the risks of coronary surgery. Even more complex lesions, such as LMCA bifurcation can be treated with success and immediate improvement in the patient. 
In the present case, once more, it is clear that unprotected LMCA is not taboo for cardiology intervention: stent deploy- ment of unprotected LMCA in selected cases can be a perfect choice, saving time and reducing morbidity and mortality.

\section{References}

1. Mehan VK, Salzmann C, Pfammatter JP, Stocker FP, Meier B. Left main coronary angioplasty in a 10-year-old boy with homozygous familial hypercholesterolemia. Cathet Cadiovasc Diagn 1993; 29: 24-7.

2. ErbelR,MeinertzT,WesslerI,MeyerJ, Seybold-Epting W. Recanalization of occluded left main coronary artery in unstable angina pectoris. Am J Cardiol 1984; 53: 1725-7.

3. Park SJ, Park SW, Hong MK, et al. Stenting of unprotected left main coronary artery stenoses: immediate and late outcomes. J Am Coll Cardio 1998; 31: 37-42.
4. O'Keefe JH, Hartzler GO, Rutherford BD, et al. Left main coronary angioplasty: early; late results of 127 acute and elective procedures. Am J Cardiol 1989; 64: 144-7.

5. Ellis SG, Tamai H, et al. Contemporary percutaneous treatment of unprotecded left main coronary stenosis. Circulation 1997; 96: 3867-72.

6. Shin EK, Ahn TH, et al. Stenting of an unprotected bifurcating (left main, circumflex) lesion. J Invas Cardiol 1998; 10: 339-41. 